\title{
Transitioning from registered nurse to clinical nurse educator in the year of the nurse and midwife
}

\author{
Valerie Heathcote*1, Janet Green ${ }^{2}$ \\ ${ }^{1}$ Liverpool Hospital, Sydney, Australia \\ ${ }^{2}$ School of Nursing, College of Health and Medicine, University of Tasmania, Sydney, Australia
}

Received: November 17, 2020

DOI: $10.5430 /$ jnep.v11n4p52
Accepted: December 16, 2020 Online Published: December 22, 2020

URL: https://doi.org/10.5430/jnep.v11n4p52

\begin{abstract}
Clinical nurse educators provide educational support for clinicians delivering direct patient care. This is an important function that demonstrably increases the application of Evidence Based Practice. The transition from registered nurse to clinical nurse educator is examined in a pragmatic way to offer assistance to those effected by the role change. This paper has ultilized an integrative review to examine literature about the transition from registered nurse to clinical nurse educator. Numerous aspects of the transition are considered including some of the changes that are occurring and their potential impact. Negative experiences that may be encountered have been explored and strategies suggested to ameliorate them. Discussion has been provided on the importance of professional development, self-understanding and reflective practice. Consideration is given to orientation and communication, the competence required, and the benefits of collegial relationships. The very presence of a high performing clinical nurse educator can also have a direct effect on the culture of a workplace to encourage nurses towards professional growth by providing ongoing learning through organisational and self-directed education. The purpose of this paper is to provide some practical insights and strategies for assisting this transition, particularly in the year of the nurse and midwife.
\end{abstract}

Key Words: Transition, Nurse, Educator, Clinical

\section{INTRODUCTION}

The year 2020 has been named the year of the Nurse and Midwife. ${ }^{[1]}$ International Nurses Day is observed every year on May 12th, the date of Florence Nightingale's birth. The year 2020 was also the 200th birthday of Florence Nightingale, and because of the global impact that Nightingale has had on nursing and health care, the United Nations issued a stamp to commemorate her 200th birth anniversary. ${ }^{[2]}$ When Florence Nightingale returned from the Crimean War she established the Nightingale Nursing School at St Thomas's Hospital in London in 1860. This was considered to be the first nursing school in the world. Nightingale is credited with pioneering the concept of nursing education for nurses, and since that time nurse education has been transferred into universities and nurses have extended and expanded their roles to meet the challenges in health care in a rapidly changing world.

One role that has been extended and expanded is that of the clinical nurse educator (CNE). The CNE role is traditionally a nursing position recruited from "bedside" registered nurses (RNs). The $\mathrm{RN}$ has the primary responsibility for providing physiological and psychosocial patient care in a variety of settings. The $\mathrm{RN}$ supervises and delegates nursing activity to enrolled nurses (ENs) and other staff appropriate to their level of ability and expertise, with consideration of

\footnotetext{
*Correspondence: Valerie Heathcote; Email: valerie.heathcote@health.nsw.gov.au; Address: General Managers Unit, Liverpool Hospital, Locked Bag 7103, Liverpool BC 1871, Australia. 
their learning needs. ${ }^{[3]}$

The $\mathrm{RN}$ requires critical thinking skills to analyse data before embarking on a case, shift, or care episode. It is important that the RN has a clearly planned care model with flexibility to adapt to admissions, absences, emergencies and discharges. ${ }^{[4]}$ The RN also engages in effective relationships with his/her team to ensure that appropriate and evidencedbased care has been provided, based on agreed plans with revision of these plans as required. ${ }^{[3]}$

The role of the CNE is different and he/she is required to deliver nursing education, contribute to the professional development of colleagues, support, precept and orientate staff whilst supporting clinical skill development. ${ }^{[5]}$ It is acknowledged that there is a strong link between the application of evidence-based practice (EBP) and nursing education. ${ }^{[6]}$ In fact, CNEs have a mandate to facilitate, reinforce and model EBP. ${ }^{[7,8]}$ However, there is no clear articulated transition from RN to CNE, and it is not clear whether the RN possesses the educational qualifications and ability to teach effectively. There is little doubt that RN's have the clinical ability and credibility, however the CNE and anyone who teaches nurses, requires different skills. Perhaps the difference is the nurse educator requires knowledge of educational theories, assessment and evaluation methods. This is discussed further under competence, with postgraduate educational study being recommended for RNs interested on pursuing a career in nursing education.

In Australia, during the 1980's nursing education commenced a period of change from being hospital-based to being taught in university settings, with practical clinical experience components in local hospitals. By 1993, all nursing students in Australia who wanted to be RN's were entering the profession via the university education pathway, and emerging with a diploma or degree. ${ }^{[9]}$ This means that in 2020 nursing education has been in the tertiary sector for 27 years. The average age of nurses in Australia is 44.4 years, with $39 \%$ aged 50 years and over. ${ }^{[10]}$ RN's, including CNEs, clinical nurse consultants (CNCs), and nurse unit manager (NUMs) who are working currently could have been graduates of a hospital-based nursing education program. Without seeking to be elitist, there are major differences between the educational preparation of nurses in the hospital-based education and tertiary-based systems, therefore it could be argued that hospital-based nurses who have not updated their qualifications through a university qualification, may not be best placed to teach students who will graduate from university. The current hospital qualification, the Certificate in Nursing is a level four (Cert IV) on the Australian Qualifications Framework (AQF). The Cert IV requires the application of

Published by Sciedu Press skills and knowledge; however, it includes a limited responsibility for organising others. By comparison the university nursing qualification Bachelor of Nursing is a Level seven AQF and graduates of a bachelor's degree are expected to have the cognitive skills to demonstrate broad understanding of issues, exercise critical thinking and judgement to identify and solve problems. The are required to possess communication skills to present a coherent, clear independent exposition of ideas and knowledge. ${ }^{[11]}$

A link has already been established between the level of education of the nurse and patient outcomes. Aiken and Sloane ${ }^{[12]}$ found that when there were a greater proportion of university educated nurses at the bedside it was associated with better outcomes for patients. Increasing the numbers of assistive personnel without professional nursing qualifications may contribute to preventable deaths, erode care quality, and contribute to nurse shortages. Yakusheva et al. ${ }^{[13]}$ found that a $10 \%$ increase in the number of baccalaureate-degree prepared nurses lowered the odds of patient mortality by $10.9 \%$. If the degree prepared nurses provided $80 \%$ of the patient care it would result in significantly lower readmission rates, shorter lengths of stay and cost savings. Furthermore, Kendall-Gallagher ${ }^{[14]}$ found if the degree prepared nurses were also certified in their specialty, it was associated with a decrease in patient mortality and "failure to rescue". [14] While there is a link between the education of nurses and patient mortality, no such research exists that shows that education at a ward level has an impact. Anecdotal evidence and watching how nurses respond to emergencies, would suggest that a link exists.

Transition has been defined as "the process or a period of changing from one state or condition to another", ${ }^{[15]}$ or in the case of this paper, the transition from $\mathrm{RN}$ to $\mathrm{CNE}$. Transitions involve beginnings and endings, which require relinquishment of previous roles. ${ }^{[16]}$ This means that an $\mathrm{RN}$ must surrender his/her previous clinical position before he/she can move into the CNE position. Relinquishment can be problematic, as the professional or career identity for nurses develops and evolves throughout their careers. Despite moving into a teaching role, the professional identity can be firmly linked to their clinical role. Role changes or transitions can occur throughout a nurse's career, from undergraduate, to $\mathrm{RN}$ and then subsequently through various clinical practice roles, scopes and settings. International literature uses alternate terminology making comparisons complicated because they may use the terms teachers, facilitators, faculty, nurse educators (NE) or hospital based CNEs depending on the country of residence. The purpose of this paper is to examine the qualities of this transition through practical insights and highlight evidence-based strategies for the benefit of 
current stakeholders to assist this delicate transition, particularly in the COVID-19 environment. For the purposes of this study any paper that referred to educators performing clinical teaching were included, this enabled a global perspective to evolve. Both authors of this paper were educated in the hospital-based nursing system and have transitioned from clinical to educator roles, and one has transitioned to academia.

\section{METHOD}

An integrative review methodology was utilised as it enables a broad review and facilitates a comprehensive understanding of the phenomenon. The literature was gathered using a framework outlined in Arksey and O'Malleys 5 step method. ${ }^{[17]}$ Relevant and recent literature from 2008-2020 was identified using databases to access the literature in this review. Singular or combined search terms used were 'clinical', 'nurse', 'educator', 'facilitator', 'role', 'transition' and 'new'. English language and full text. Web sites were examined for government reports and other relevant documents. Secondary references were sourced where relevant and manual examination of particular journals provided further papers. The critical evaluation of the articles required an organized approach to the characteristics and rigor of each article to determine its suitability for inclusion. In the case of primary research, the validity of the methods and results help determine their usefulness. ${ }^{[18]}$ Several papers employed a qualitative methodology, and this is considered an appropriate method for investigating attitudes and beliefs. ${ }^{[18]}$ There were 14 non - empirical papers and 11 research papers were retrieved and appraised. Thematic analysis was used to identify themes within the selected literature. The researchers examined the manuscripts to identify common themes related to transition from RN to CNE. The themes identified were:

- Change

- Negative experiences

- Professional development, self-understanding and reflective practice

- Orientation and communication

- Competence

- Collegial relationships

- Culture.

\section{Results}

When analysing the papers, it is noteworthy that author bias could be possible in many of these papers, as they are describing programmes designed by themselves or their associates. Research is limited into the preparation requirements of clinical teachers; the focus of most research has been on academic faculty which has been rejected as being outside the scope of this review. There was a paucity of research on beginning CNEs, therefore retrospective analysis was included. Whilst the validity of competence assessment is also outside the scope of this paper, they provide definitions and guidance. ${ }^{[19]}$ Research into nurse role transition has occurred for many years; evidence of uptake of their recommendations is scant and future recommendations for practice are surprisingly unchanged.

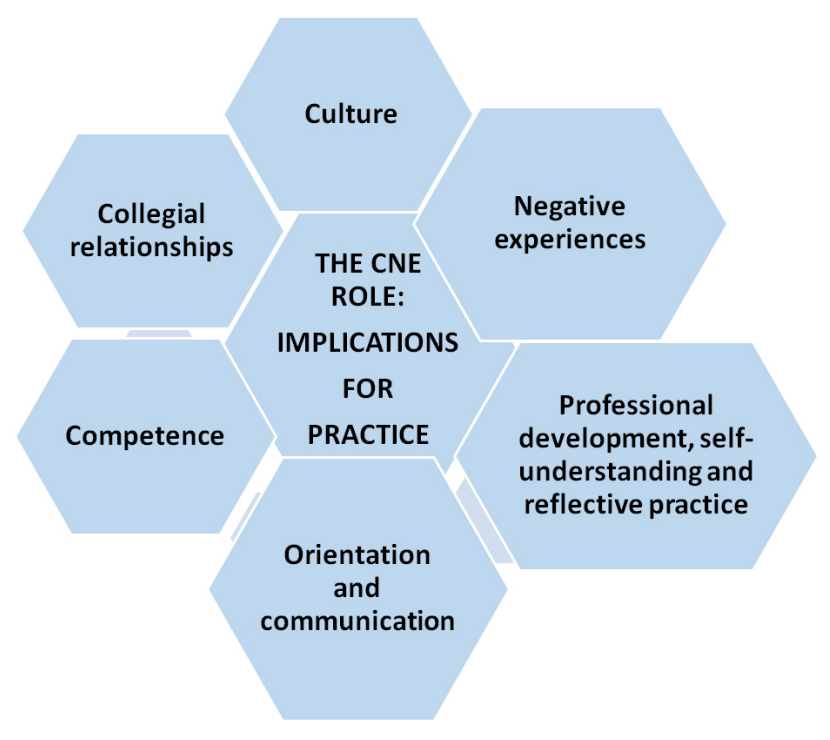

Figure 1. Research themes

\section{Discussion}

\subsection{Change}

Massive changes including electronic information and technology, staff shortages, increased patient complexity and acuity, shifting sands in the understanding of diseases such as COVID 19, and organisational redesign are impacting on numerous aspects of the roles of CNEs. ${ }^{[20]}$ During the Crimean war, Florence Nightingale blamed deplorable conditions in the hospitals for the tenfold higher mortality rates amongst inpatient soldiers to disease, rather than on the battlefield. ${ }^{[21]}$ Nightingale is recognised as a foundation creator of the concept of EBP. ${ }^{[22]}$

In 1982 it was noted by Benner ${ }^{[23]}$ that nursing was so complicated it was impossible to standardise, however recently, standardisation is achieved using policy to implement EBP. EBP is the integration of patient values, the best evidence and clinical expertise into decision making processes for patient care. $^{[24]}$

Benner's seminal paper and book, "From Novice to Expert", ${ }^{[23]}$ reports on 67 interviews with nurses on their role transition, including anecdotes, confirming evidence supporting the Dreyfus model. The Dreyfus model describes 
five stages where learners coach others and work more autonomously as they move from novice to expert. ${ }^{[25]}$

Fritz ${ }^{[26]}$ highlighted issues faced by nurses whose work involves education related to their need to be proficient in two professions: nursing and education. Deficiencies in their proficiency in teaching or nursing were exacerbated by inadequate preparation or unrealistic expectations when the $\mathrm{RN}$ entered the role. Professionals undergoing such role alteration encounter conditions that influence the quality of the change, including their expectations versus the reality, their skill and knowledge level, environmental complexities and wellbeing. ${ }^{[27]}$ If the environment is transitional at the organisational level with changes occurring in function, dynamics or structure of the organisation, the maturation of the CNE is impeded. In other words, too much change all at once makes the transition from RN to CNE more challenging. This literature review by Schumacher and Meleis ${ }^{[27]}$ proposed a model to apply transition as a concept central to nursing which advanced previous knowledge, and remains a relevant study particularly in this era of ongoing change where many CNE's are "acting" in their roles.

A non-experimental design was employed in a Canadian survey of 209 hospital nurses who primarily provide "in-service education' by Davies et al. ${ }^{[28]}$ This study may be relevant given the similarities between the Canadian and Australian health systems. ${ }^{[29]}$ For example the percentage of nurses performing non-standard work, either part time, agency or casual has increased. ${ }^{[30]}$ In Canada the non-standard workers comprise $42.6 \%$ of the $\mathrm{RN}$ workforce and in Australia it is even higher with part time RNs $48.8 \%$ of the workforce. ${ }^{[10,31]}$ These larger cohorts of casual nurses require more frequent orientations and increasingly sophisticated technology necessitates ongoing training, which adds to the CNE role complexity and workload. ${ }^{[28]}$ Organisational redesign affected status, job satisfaction and perceived empowerment by multiplying the complexity of the role. This led the authors to recommend each CNE supports a single clinical area. Financial constraints limit resources and staff development opportunities, adding to reduced nursing numbers caring for more patients with higher acuity, thereby further exacerbating pressure on CNEs. ${ }^{[28]}$ Staff shortages were identified as a theme in the literature. Jarrett et al. ${ }^{[32]}$ identified educator shortages were aggravated by the pay gap between nurses and educators, where clinical RNs can earn much more than their educator colleagues due to the industrial benefits of shift work. This issue has not been resolved due to burgeoning health care costs and an inability to provide wage increases to educators. These pressures have increased during the COVID-19 pandemic. The Royal College of Nursing (RCN) surveyed 42,000 members in the National Health Scheme this year and $73 \%$ responded stating that higher wages would make them feel more valued. ${ }^{[33]}$ This may touch a nerve with New South Wales, Australia nurses who have had their regular consumer price index (CPI) wage equalisation, not pay rise, reduced by their state Government. Over $36 \%$ of the RCN (2020) respondents were considering leaving nursing with pay being the primary factor $(61 \%)$, and the way they have been treated during the COVID-19 pandemic (44\%), low staff levels $(43 \%)$ and lack of support from management $(42 \%){ }^{[33]}$

\subsection{Negative experiences}

Multiple negative aspects to this role changeover were identified in the literature surrounding stress, lack of control and reality versus perception. The internalised theoretical frameworks that English nurse teachers make sense of their assorted work roles was studied in 1985 when factors mitigating against clinical teaching were investigated. ${ }^{[34]}$ Respondents were negatively orientated to clinical teaching due to lack of control, conflict and stress within the work role environment. Coincidentally, in a study by Jones et al. ${ }^{[35]} 40 \%$ of CNE's had less than two years' teaching experience and barriers were constructed by the staff to avoid the ward teaching situations. Teaching activities reflect highly technical practices, and nurse teachers maybe fearful and anxious that they had not adequate maintained their currency of clinical knowledge. ${ }^{[36]}$ Wenner and Hakim conducted a phenomenological study exploring the role transition of CNE's employed in both clinical and Faculty Positions. The modern phenomena of the part time academic and part time clinician was examined where work-role transition was multifactorial and highly individualised. ${ }^{[37]}$ The seven themes they identified included different backgrounds and experiences; support and guidance; challenges; the maintenance of two work roles; the influence of prior experience and personal attributes. Role confusion was exacerbated when a nurse served in more than one role in the same unit, such as being both a clinical RN and a clinical nursing educator. These challenges are in many ward environments, however clear establishment of local requirements and expectations can assist both the educator and the clinical nurse to focus and prioritise learning.

All RNs must utilise lifelong learning for continuing professional development, and teaching others is a fundamental aspect of their role, ${ }^{[3]}$ making this aspect of practise aligned to the CNE role. Avoidance of clinical teaching is an understandable strategy with difficulties experienced around role. ${ }^{[38]}$ Utilising grounded theory Neese ${ }^{[39]}$ captured the career path of nurse to teacher. The emergent themes were "troublesome duality", position change, lack of affirmation, serving your time and "teaching in the dark". Some of these 
difficulties may be ameliorated by recognising the ability to be a "guide on the side" rather than a "sage on the stage" as an important educational technique. ${ }^{[39]}$ This might be a useful, if labour intense, method to cultivate a learning community and manage teaching in the modern volatile bedside clinical environment. It should be remembered that whilst clinical expertise is important for a CNE, this knowledge and skill may not always translate into teaching expertise. ${ }^{[40]}$

Other negative themes related to stress associated with transition have been identified in the literature. Lewallen et al. ${ }^{[41]}$ identified stress as a factor in the current faculty. A small but rigorous phenomenological study by Schriner, ${ }^{[42]}$ examined the effect of culture on the change of nurses to clinical faculty roles. Six themes emerged including expectations versus reality, stressors of transition, insufficient pedagogical role preparation, realities of the clinical milieu, student culture and hierarchy and reward. Intra-role conflict can culminate in a further increase in workload, because people have different expectations of what the CNE should be doing; leading to longer work hours. ${ }^{[43]}$

\subsection{Solutions}

\subsubsection{Professional development, self-understanding and reflective practice}

Numerous authors have recommended specific teacher training for nurses, professional development pathways and reflective practice to aid the conversion to educator. ${ }^{[26,40,43]}$ Krisman-Scott et al. ${ }^{[44]}$ reviewed their programme to increase teaching skills of graduate nurses addressing role transition stress. This recommendation was designed to alleviate some of the transition stressors. The Finnish 'Teacher candidates' reflective teaching and learning in a hospital setting' advocates for enhanced abilities, in-service theory application and improved reactive staff discussions. These findings are possible, particularly given the recognised power of reflective practice. ${ }^{[45]}$

Cangelosi et al. ${ }^{[46]}$ emphasise the importance of written reflective narratives of student educators to help them transition from clinical experts to beginner teachers. ${ }^{[46]}$ Learning to teach as a distinct phenomenon was identified as important area, because teaching has its own skill set, distinct from clinical practice. The benefits of teaching qualifications would seem obvious, however Barbé and Kimble ${ }^{[47]}$ raise the concern about the cost of further education. One master's programme described by Neese discusses graduate articulation amid the transformational nature of her teaching and learning experience to became critically reflective. ${ }^{[39]}$ Neese advocates graduate studies to learn teaching skills, particularly ones that involves mentored teaching practise. This paper provides insightful solutions in the process of becoming a teacher.

Learning portfolios can assist with documentation of the new role and reflection on the previous role. This provides transformational learning opportunities within teaching practice. ${ }^{[4]}$ Green et al. ${ }^{[49]}$ have articulated the positives and challenges of using an electronic or E-Portfolio to capture professional development. Jarrett et al. found that providing the opportunities for nurses to learn to teach resulted in retention of staff, more professional collaboration, job satisfaction and enjoyment of learning. ${ }^{[32]}$

Janzen ${ }^{[16]}$ constructed a conceptual model that provides a thorough understanding of the "self" contributes to RNs actualising into a CNE. Higgs and Mac Allister offer insights into the role of clinical educators (CE) and could be transferable to other health professionals. ${ }^{[50]}$ Themes identified included a sense of self, agency, growth and development, relationships with others and being a CE. Professional development to heighten self-awareness and achieve dynamic blending of all dimensions of self-congruence is recommended and this aligns with other research. ${ }^{[50]}$

\subsubsection{Orientation and communication}

Orientation and open communication are recommended to assist neophyte educators. McKinley ${ }^{[51]}$ has emphasised the importance of individually tailored orientations to facilitate an effective role conversion to CNE. Others, including Kearney propose that neophyte teachers need help to ensure they transition into the profession, however further research is needed across various sites to demonstrate transferability. ${ }^{[52]}$

Manning and Neville interviewed eight New Zealand CNEs, finding that the CNE role was more complex than expected with signs of stress evident because they had not been prepared for the role. ${ }^{[53]}$ The authors recommended individually tailored orientation periods to transition successfully to CNE. Hewett and Lewallen provided individually tailored orientation for CNE's emphasising the importance of preparation to the clinical area thorough extensive orientation. ${ }^{[54]}$

Ramage found that role understanding and competence emerged as vital to smooth conversion to CNE. ${ }^{[55]}$ This research investigated how people adapt to new roles and four categories emerged, 'negotiating credibility', 'gaining access', 'being effective', and the core theme 'negotiating multiple roles' ${ }^{[55]}$ Old identities were discarded when the new role was adopted, and this disassembling, reconstructing and, lastly realising the self. ${ }^{[55]}$ Ramage recommends further research into the impact of group dynamics on educational roles, as well as the impact of educational roles on clinical practice. ${ }^{[55]}$ The identification of change agents and work and the establishment strong social ties with senior staff was 
recommended. ${ }^{[55]}$ Davies et al. ${ }^{[28]}$ recommend CNE's are provided with a current and clear job definition, increasing visibility, allowing discrete decision making, effective communication methods, regular meetings regarding equipment, procedure, or practice changes and finally access to adequate resources and support. Cooley and De Gagne established an internship programs and concluded that mentorship would contribute to competence in novice nursing educators. ${ }^{[56]}$ Arrowsmith et al. conducted a systematic review of the literature and recommended a supportive environment that demonstrates an understanding of the process of transition to ensure their success. ${ }^{[57]}$

\subsubsection{Competence}

The World Health Organisation (WHO) ${ }^{[58]}$ developed nurse educator core competencies, and this document reflects the need for clinical competence, and the organisational and communication skills that RN's possess. However, the nurse educator requires sound teaching and assessment skills reflective of an adult learning approach. A leadership role in the nursing profession, and acting as a change agent and a role model for students, are important for nurse educators While RN's socialise students into the profession, the focus is often on the needs to the facility, and not the learning needs of students, however nurse educators also consider the learning needs of learners as part of the socialisation process. ${ }^{[58]}$ Existing competencies for nurse teachers require regular review. ${ }^{[59]}$ A proficient teacher has a mean of 12.1 years' teaching experience, emphasising that novice nurse educator staff development is essential. ${ }^{[59]}$ The Australian Nurse Teacher Society's competencies were evaluated for job descriptions, performance appraisals, portfolio development and practice reflection. These competencies may also assist neophyte educators to understand their role more comprehensively from the outset. ${ }^{[59]}$

The complexity of the CNE role was addressed by McKinley. ${ }^{[51]}$ Competing demands of the role included professional development, clinical competence, visibility and workload. The transition to CNE could be assisted with greater clarity of role responsibility and clear, open communication, assessment and evaluation that is ongoing, and self-care behaviour is valued. Organisations should invest in ongoing staff resilience and self-care programmes to help prepare staff to accomplish the organisational mission and provide high quality patient care. ${ }^{[60]}$

Managers can promote self-care behaviour and resilience by co creating wellbeing resources. ${ }^{[61,62]}$ One Australian example of such a programme is the New South Wales Health's (NSW) Meditation-based Wellness and Compassion (MWAC) activity led by Nickolas $\mathrm{Yu}$, who founded $\mathrm{Hu}-$ mankind Meditation. ${ }^{[63]}$ Meditation and compassion training can increase prosocial behaviour, emotional regulation and resilience which are particularly beneficial for nurses. ${ }^{[64]}$

\subsubsection{Collegial relationships}

Nursing role transitions were widely discussed as early as 1994, and a mentor was identified as an important resource to smooth the transition. ${ }^{[27]}$ Since then numerous authorities have recommended mentorship to aid this evolution to CNE. ${ }^{[28,45,50,51,53,65,66]}$ Wills and Kaiser ${ }^{[67]}$ examined mentoring from the perspective of the protégé. They emphasised that mentoring was stressful for the protégé and they gave guidance on how to reduce the stress by knowing oneself, being realistic, mingling, negotiating and learning. ${ }^{[67]}$ Identifying a suitable mentor match was also noted as important. In 2003 Lewallen et al. outlined a support group and mentoring as a safe avenue for stress venting. ${ }^{[41]}$ More recently, in 2018, Disch discussed how healthcare and society are becoming increasingly more complex, and healthcare professionals should consider new options for developing their capabilities and competence. ${ }^{[66]}$ To evolve as a well-rounded educator, expertise and experience is required which may be achieved with multiple mentors with a shorter relationship duration. ${ }^{[66]}$

Nursing Schools are instituting mentoring and orientation to expedite the change from nursing to teaching. ${ }^{[68,69]}$ Benefits for the mentee include smoother role transition, decreased isolation, higher salary, faster promotion and higher satisfaction levels. In a study by Jantz educators with 10 years' experience had their perspectives relating to their role explored. ${ }^{[70]}$ Themes identified included believing in others and oneself, passion about the occupation, investing in relationships and acting harmoniously. ${ }^{[70]}$ Mentoring and training new educationalists are strategies to alleviate staff shortages. In fact, lack of mentorship was identified as a consistent source of frustration. ${ }^{[46]}$ While mentoring has been associated with many positives, and it has been found that the nursing literature largely reflects the positive aspects of mentoring, there is some evidence to suggest that negative and even toxic mentoring relationships are not uncommon and that these relationships can, in some situations, become destructive. ${ }^{[49]}$

In a paper titled "Tips for the Uninitiated" to guide new nurse education facilitators in Canada ${ }^{[71]}$ the tips for success included staying focused, successful goal setting, know the subject matter, keep presentations brief, use quick reference guides, know the audience, be flexible, get managers cooperation and support, provide snacks or incentives, find mentors and personal supports and start with teams that are open to change. ${ }^{[71]}$ Kalb describes how a Nursing College in Min- 
nesota, USA uses academic NEs core competencies of to guide their graduate programme. The neophyte NE completes self-evaluations during mentoring which are collated in portfolios. ${ }^{[72]}$ This is a demonstration of the increasingly formalised and structured approach the nursing profession has taken.

\subsubsection{Culture}

Nursing culture has been the subject of much discussion since 1986 when Meissner wrote "nurses: are we eating our young".[73] The Joanna Briggs Institute supported a systematic review of qualitative evidence examining the influence of workplace culture on nurses' learning experiences. ${ }^{[74]}$ Fourteen articles identified a total of 105 findings which were grouped into two synthesized findings, organizational influences and relational dynamics. Organisational influence enables the nurse to demonstrate accountability for their own learning, together with systems that provide time, resources, adequate support and staffing which displays encouragement and values the nurses' education and learning. Relational dynamics was demonstrably valued by the nurses, and this included preceptors, peers, mentors, expert nurses plus educators encouraging and facilitating their professional development. The authors found that optimal workplace culture was fundamental for nurses to experience relevant and valuable workplace learning. ${ }^{[74]}$ It was recommended that a dual system with organisational structure valuing their learning enables nurses to establish accountability for their own professional development.

- To improve team cohesiveness through increased professional participation of each nurse in his/her unit.

- To emphasise a positive culture in which nurses are encouraged to grow professionally.

- To support a culture of ongoing learning through organisational and self-directed education.

- Increase nurse retention and satisfaction by providing professional development opportunities.

- To enable nurses to develop their own a unique unit-specific concept map and milestone pathway to tailor their own professional development plan in conjunction with CNEs, NUMs, senior RNs and CNSs.

- Enables NUMs to evaluate the progress of nurse's professional development.

- Assist CNEs to structure learning plans for nurses.

- Improved patient care as a result of increased provision of nurse education.

\subsection{Implications for research}

The implementation and effectiveness of many of the recommendations made in this paper require further research. Indeed, there has only been one interventional study into the transition of RNs from the bedside to CNE in the inpatient setting and none in an outpatient setting, which indicates the need for further research, particularly in Australia. ${ }^{[26]}$ Most of the literature surrounding the evolution of bedside nurses to CNEs recommends mentorship without evaluating its effectiveness, or whether the mentorship occurs. Consideration of this would inform practice and research into both mentor selection, and their capacity to cross different clinical areas and would assist future beginner CNEs. The repercussions of CNE teams covering broad clinical areas instead of single units requires closer scrutiny. The impact CNEs have on practise and patient outcomes could also be examined further to evaluate their effectiveness. Another area for potential future research could be the effect of group dynamics on educational roles. The question of whether NE competencies are applicable to CNEs is another aspect requiring closer examination. The transition of bedside nurse to $\mathrm{CNE}$ is an under evaluated topic, and one that has the potential to improve patient outcomes.

\section{Conclusion}

This literature review of over 33 year's research has demonstrated there are numerous recommendations for practice to ease the sometimes-difficult transition of bedside RN into CNE. Huge changes are currently affecting CNEs, including new diseases to manage such as COVID-19, new technology, staff shortages, temporary positions, higher patient acuity and greater financial strain. Nurses in NSW, Australia would appreciate the New South Wales Government permanently reinstating wage equalisation with the Consumer Price Index as an act of good will in recognition of the hard work and sacrifice they make. It is evident over time that nursing has adopted a more formalised structured approach to deal with the challenges of the unstable environment to implement EBP. Much stress results from the negative experiences during this phase including the reality being more complex, or not matching expectations. Other issues include workload pressures, inadequate role preparation and knowledge base and perceived reward imbalances. These issues may be alleviated by post graduate education, professional development, understanding of self, reflective practice, orientation and communication, competencies and collegial relationships. Understanding of the ANTs competencies will assist role clarity. Recognition of the importance of clinical teaching and a supportive learning environment could potentially narrow the theory practice gap. Behaving harmoniously eases the transition, however if EBP is not adopted there may be a poor organisational fit. Finally, to the emerging CNE, take note, you are not alone! 


\section{ACKNOWLEDGEMENTS}

We would like to thank all staff who contribute to the care for our patients and management who support this care and

\section{REFERENCES}

[1] World Health Organization. 2020 - Year of the Nurse and the Midwife 2020. (c) Copyright World Health Organization (WHO), 2020. All Rights Reserved. Available from: https://www. who.int/ca mpaigns/year-of-the-nurse-and-the-midwife-2020

[2] The United Nations Postal Administration. UN Stamp Celebrates Florence Nightingaleas. 200th Birthday Permanent Missions 2020. Available from: https://www.un.int/news/un-stamp-celebrate s-florence-nightingale $\% E 2 \% 80 \% 99 s-200$ th-birthday

[3] Nursing and Midwifery Board of Australia. Registered nurse standards for practice. Melbourne. 2016.

[4] Hansten RI. A Bundle of Best Bedside Practices: Field Evidence. The Health Care Manager. 2009; 28(2): 111-6. PMid:19433928 https://doi.org/10.1097/HCM.0b013e3181a2cb0b

[5] Industrial Relations Commission Of New South Wales. Public Health System Nurses' And Midwives' (State) Award 2017. In: Industrial Relations Commission Of New South Wales, editor. Sydney. 2017.

[6] Gawlinski A, Rutledge D. Selecting a model for evidence-based practice changes: a practical approach. AACN Advanced Critical Care. 2008; 19(3): 291-300. PMid:18670204 https://doi.org/10.1 097/01.AACN.0000330380.41766.63

[7] Hewitt-Taylor J, Heaslip V, Rowe NE. Applying research to practice: exploring the barriers. British Journal of Nursing. 2012; 21(6): 3569. PMid:22584932 https://doi.org/10.12968/bjon.2012.2 1.6.356

[8] Penz KL, Bassendowski SL. Evidence-based nursing in clinical practice: implications for nurse educators. The Journal of Continuing Education in Nursing. 2006; 37(6): 250-4. PMid:17144114 https://doi.org/10.3928/00220124-20061101-03

[9] Australian Government Department of Health. Review of Australian Government Health Workforce Programs, Nursing and midwifery education. 2013

[10] Australian Institute of Health and Welfare. Nursing and midwifery workforce 2015. Canberra. 2016.

[11] Australian Government. Australian Qualifications Framework 2020. Available from: https://www .aqf .edu.au/

[12] Aiken L, Sloane D, Griffiths P, et al. Nursing skill mix in European hospitals: Cross-sectional study of the association with mortality, patient ratings, and quality of care. BMJ Quality \& Safety. 2017; 26(7): 559-68. PMid:28626086 https://doi.org/10.1136/bm jqs-2016-005567

[13] Yakusheva O, Lindrooth R, Weiss M. Economic evaluation of the $80 \%$ baccalaureate nurse workforce recommendation: a patientlevel analysis. Medical Care. 2014; 864-9. PMid:25215646 https: //doi.org/10.1097/MLR.0000000000000189

[14] Kendall-Gallagher D, Aiken LH, Sloane DM, et al. Nurse specialty certification, inpatient mortality, and failure to rescue. Journal of Nursing Scholarship. 2011; 43(2): 188-94. PMid:21605323 https://doi.org/10.1111/j.1547-5069.2011.01391.x

[15] Oxford Dictionary on Lexicocom. Oxford2020. Meaning of Transition.

Published by Sciedu Press the research that underpins EBP.

\section{CONFLicts OF INTEREST Disclosure}

The authors declare that there is no conflict of interest.
[16] Janzen KJ. Alice Through the Looking Glass: The Influence of Self and Student Understanding on Role Actualization Among Novice Clinical Nurse Educators. The Journal of Continuing Education in Nursing. 2010; 41(11): 517-23. PMid:20672756 https : //doi.org/10.3928/00220124-20100701-07

[17] Arksey H, O’Malley L. Scoping studies: towards a methodological framework. International Journal of Social Research Methodology. 2005; 8(1): 19-32. https://doi.org/10.1080/136455703200 0119616

[18] Litva A, Jacoby A. In: Craig RSJ, editor. The evidence - based practice manual for nurses. 2nd ed. Philadelphia: Elsevier; 2008; $154-83$.

[19] National League for Nurses. Core competencies of nurse educators with task statements. New York. 2005.

[20] Duffield C, Diers D, O’Brien-Pallas L, et al. Nursing staffing, nursing workload, the work environment and patient outcomes. Applied Nursing Research. 2011; 24(4): 244-55. PMid:20974086 https://doi.org/10.1016/j.apnr.2009.12.004

[21] Fee E, Garofalo ME. Florence Nightingale and the Crimean War. Am J Public Health. 2010.

[22] McMenamin A, Sun C, Prufeta P, et al. The evolution of evidence-based practice. Nursing Management. 2019; 50(9): 14 9. PMid:31460893 https://doi .org/10.1097/01. NUMA.0000 $579000.09987 . \mathrm{b} 0$

[23] Benner P. From Novice to Expert. The American Journal of Nursing 1982; 82(3): 402-7. https://doi.org/10.1097/00000446-198 282030-00004

[24] Sackett D, Strauss D, Richardson W, et al. Evidence-based medicine: how to practice and teach EBM (2 edn.) Churchill Livingstone. New York. 2000.

[25] Dreyfus SE. Formal models vs. human situational understanding: Inherent limitations on the modeling of business expertise. Office Technology and People. 1982; 1(2/3): 133-65. https ://doi.org/ $10.1108 /$ eb022609

[26] Fritz E. Transition From Clinical to Educator Roles in Nursing - An Integrative Review. Journal for Nurses in Professional Development. 2018; 34(2). PMid:29481461 https://doi.org/10.1097/NND. 0000000000000436

[27] Schumacher KL, Meleis AI. Transitions: a central concept in nursing. Image-the Journal of Nursing Scholarship. 1994; 26(2): 11927. PMid:8063317 https://doi.org/10.1111/j.1547-5069. 1994.tb00929.x

[28] Davies MA, Laschinger HKS, Andrusyszyn MA. Clinical educators' empowerment, job tension, and job satisfaction: A test of Kanter's theory. Journal for Nurses in Professional Development. 2006; 22(2): 78-86. PMid:16603905 https://doi.org/10.1097/0012 4645-200603000-00007

[29] Borycki EM, Foster J, editors. A comparison of Australian and Canadian informatics competencies for undergraduate nurses. Nursing Informatics; 2014. 
[30] Becker S, McCutcheon H, Hegney D. Casualisation in the nursing workforce-the need to make it work. Australian Journal of Advanced Nursing. 2010; 28(1): 45.

[31] International Council of Nurses. Nursing Workforce Profile Database Summary. 2015.

[32] Jarrett S, Horner M, Center D, et al. Curriculum for the development of staff nurses as clinical faculty and scholars. Nurse Educator. 2008 33(6): 268-72. PMid:18981909 https://doi.org/10.1097/01 .NNE.0000334793.53170.1b

[33] Royal College of Nursing. Start nursing pay discussions now, says $\mathrm{RCN}$ as government announces other public sector settlements 2020 Available from: https://www.rcn.org.uk/news-and-events/ news/sco-member-survey-findings- 210820

[34] Jones JA. A study of nurse tutors' conceptualization of their ward teaching role. Journal of Advanced Nursing. 1985; 10(4): 34960. PMid:3850101 https://doi.org/10.1111/j.1365-2648. 1985.tb00830.x

[35] Jones J, Winch S, Strube P, et al. Delivering compassionate care in intensive care units: nurses' perceptions of enablers and barriers. Journal of Advanced Nursing. 2016; 72(12): 3137-46. PMid:27398943 https://doi.org/10.1111/jan.13064

[36] Bettancourt L, Muñoz LA, Merighi MA, et al. Nursing teachers in clinical training areas: a phenomenological focus. Revista latinoamericana de enfermagem. 2011; 19(5): 1197-204. PMid:22030585 https://doi.org/10.1590/S0104-11692011000500018

[37] Wenner TA, Hakim AC. Role Transition of Clinical Nurse Educators Employed in Both Clinical and Faculty Positions. Nursing Education Perspectives. 2019; 40(4): 216-21. PMid:30807504 https://doi.org/10.1097/01.NEP.0000000000000468

[38] MacNeil M. From nurse to teacher: recognizing a status passage. Journal of Advanced Nursing. 1997; 25(3): 634-42. PMid:9080292 http s://doi.org/10.1046/j.1365-2648.1997.1997025634.x

[39] Neese R. A transformational journey from clinician to educator Journal of Continuing Education in Nursing. 2003; 34(6): 258-62. https://doi.org/10.3928/0022-0124-20031101-08

[40] Mann C. Experience of Adjunct Novice Clinical Nursing Faculty: An Interpretive Case Study. ProQuest LLC. 2013.

[41] Lewallen LP, Crane PB, Letvak S, et al. An innovative strategy to enhance new faculty success. Nursing Education Perspectives. 2003; 24(5): 257-60.

[42] Schriner CL. The influence of culture on clinical nurses transitioning into the faculty role. Nursing Education Perspectives. 2007; 28(3): 145-9.

[43] Manning L, Neville S. Work-role transition: From staff nurse to clinical nurse educator. Nursing Praxis in New Zealand. 2009; 25(2): 41-54.

[44] Krisman-Scott MA, Kershbaumer RM, Thompson JE. Faculty preparation: a new solution to an old problem. The Journal of Nursing Education. 1998; 37(7): 318-20.

[45] Australian Nurse Teachers' Society (ANTS). Australian Nurse Teachers' Competencies. 2010.

[46] Cangelosi PR, Crocker S, Sorrell JM. Expert to novice: clinicians learning new roles as clinical nurse educators. Nursing Education Perspectives. 2009; 30(6): 367-71.

[47] Barbé T, Kimble LP. What Is the Value of Nurse Educator Certification? A Comparison Study of Certified and Noncertified Nurse Educators. Nursing Education Perspectives. 2018; 39(2): 66-71. PMid:29461433 https://doi.org/10.1097/01. NEP.0000000 000000261

[48] Cangelosi PR. Learning Portfolios: Giving Meaning to Practice. Nurse Educator. 2008; 33(3): 125-7. PMid:18453930 https : //do i.org/10.1097/01. NNE.0000312181.90400.cc
[49] Green J, Wyllie A, Jackson D. Electronic portfolios in nursing education: A review of the literature. Nurse Education in Practice. 2014; 14(1): 4-8. PMid:24090523 https://doi .org/10.1016/j .nepr .2013 .08 .011

[50] Higgs J, McAllister L. The lived experiences of clinical educators with implications for their preparation, support and professional development. Learning in Health and Social Care. 2005; 4(3): 156-71. https://doi.org/10.1111/j.1473-6861.2005.00097.x

[51] McKinley MG. Walking on Water and Other Lessons Learned as a Clinical Educator. AACN Advanced Critical Care. 2008; 19(4): 388-95. PMid:18981741 https://doi.org/10.4037/15597768 $-2008-4005$

[52] Kearney S. Understanding beginning teacher induction: A contextualized examination of best practice. Cogent Education. 2014; 1(1): 967477. https://doi.org/10.1080/2331186X . 2014.967477

[53] Manning L, Neville S. Work-role transition: from staff nurse to clinical nurse educator. Nursing praxis in New Zealand inc. 2009; 25(2): 41-53.

[54] Hewitt P, Lewallen LP. Ready, Set, Teach! How to Transform the Clinical Nurse Expert into the Part-Time Clinical Nurse Instructor. The Journal of Continuing Education in Nursing. 2010; 41(9): 403-7. PMid:20506923 https://doi.org/10.3928/00220124-20100 503-10

[55] Ramage C. Negotiating multiple roles: link teachers in clinical nursing practice. Journal of Advanced Nursing. 2004; 45(3): 287-96. PMid:14720246 https ://doi .org/10.1046/j.1365-2648. 20 03.02889.x

[56] Cooley SS, De Gagne JC. Transformative experience: Developing competence in novice nursing faculty. Journal of Nursing Education. 2016; 55(2): 96-100. PMid:26814820 https ://doi .org/10. 392 8/01484834-20160114-07

[57] Arrowsmith V, Lau-Walker M, Norman I, et al. Nurses' perceptions and experiences of work role transitions: a mixed methods systematic review of the literature. Journal of Advanced Nursing. 2016; 72(8): 1735-50. PMid:26915481 https://doi.org/10.1111/ja n. 12912

[58] World Health Organisation. Nurse Educator Core Competencies 2020. Available from: https://www.who.int/hrh/nursing_midwif ery/nurse_educator050416.pdf

[59] Guy J, Taylor C, Roden J, et al. Reframing the Australian nurse teacher competencies: Do they reflect the 'REAL'world of nurse teacher practice? Nurse Education Today. 2011; 31(3): 231-7. PMid:21093124 https://doi.org/10.1016/j.nedt.2010.10 .025

[60] Shanafelt TD. Enhancing meaning in work: A prescription for preventing physician burnout and promoting patient-centered care. JAMA. 2009; 302(12): 1338-40. PMid:19773573 https ://doi . or $\mathrm{g} / 10.1001 / \mathrm{jama} .2009 .1385$

[61] Hofmeyer A, Taylor R, Kennedy K. Fostering compassion and reducing burnout: How can health system leaders respond in the Covid-19 pandemic and beyond? Nurse Education Today.

[62] Hofmeyer A, Taylor R, Kennedy K. Fostering compassion and reducing burnout: How can health system leaders respond in the Covid-19 pandemic and beyond? Nurse Education Today. 2020. PMid:32980180 https://doi.org/10.1016/j.nedt.2020.10 4502

[63] Yu N. HumanKind Meditation - Free guided meditations. 2020. Available from: https://www. humankindmeditation.com

[64] Singer T, Klimecki O. Empathy and Compassion. Current Biology. 2014; 24: R875-R8. PMid:25247366 https://doi.org/10.101 $6 / j$. cub.2014.06.054 
[65] Cullen D, Shieh C, McLennon SM, et al. Mentoring Nontenured Track Nursing Faculty - A Systematic Review. Nurse Educator. 2017.

[66] Disch J. Rethinking Mentoring. Critical Care Medicine. 2018; 46(3). PMid:29474324 https://doi.org/10.1097/CCM. 0000000000 002914

[67] Wills CE, Kaiser L. Navigating the course of scholarly productivity: The protégé's role in mentoring. Nursing Outlook. 2002; 50(2): 61-6. PMid:12029298 https://doi.org/10.1067/mno.2002.12242 9

[68] Billings DM. Developing your career as a nurse educator: the importance of having (or being) a mentor. Journal of Continuing Education in Nursing. 2008; 39(11): 490-1. PMid:19024405 https://doi .org/10.3928/00220124-20081101-09

[69] Grassley JS, Lambe A. Easing the Transition From Clinician to Nurse Educator: An Integrative Literature Review. Journal of Nursing Education. 2015; 54(7): 361-6. PMid:26155026 https : //doi . org/10 .3928/01484834-20150617-01
[70] Dattilo J, Brewer MK, Streit L. Voices of Experience: Reflections of Nurse Educators. The Journal of Continuing Education in Nursing. 2009; 40(8): 367-70. PMid:19681574 https://doi.org/10. 392 8/00220124-20090723-02

[71] Robertson K. Becoming a facilitator: tips for the uninitiated. The Canadian Nurse. 2009; 105(8): 6-7.

[72] Kalb KA. Core competencies of nurse educators: inspiring excellence in nurse educator practice. Nursing Education Perspectives. 2008; 29(4): 217-9.

[73] Meissner J. Nurses: are we eating our young? Nursing. 1986; 16(3). https://doi.org/10.1097/00152193-198603000-00014

[74] Davis K, White S, Stephenson M. The influence of workplace culture on nurses' learning experiences: a systematic review of qualitative evidence. Best Practice: Evidence based information sheets for health professionals. 2016; 274-346. PMid:27532660 https://doi .org/10.11124/JBISRIR-2016-002219 